\title{
Editorial
}

\section{Teoria y práctica de la democracia en las culturas}

Es indudable que los progresos tecnológicos han abolido prácticamente las distancias geográficas entre un pais y otro. Esto hace que el intercambio de ideas a escala mundial sea una necesidad más urgente que en el pasado. Una iniciativa que ba buscado llevar esto a la práctica ba sido el Seminario Internacional del programa de diálogo Norte-Sur, organizado por el Missionswissenschaftliches Institut Missio e.V. (MVI), de Aquisgrán, Alemania. Con el objetivo, no sólo de rendir homenaje a esta importante iniciativa, sino también de "poner ideas en circulación", $y$ de llevar a nuestros lectores algo del debate filosófico contemporáneo, hemos dedicado la presente entrega a la novena edición de dicho seminario.

El IX Seminario Internacional del programa de diálogo NorteSur, llevado a cabo en México, D.F., entre los dias 12 y 15 de marzo del presente año, se tituló Teoría y práctica de la democracia en las culturas. Se trató de un espacio donde autores de renombre en el campo de las ideas debatieron sobre los proble-

\section{5}

Teorio y práctica de la democracia en las culturas 
mas de la democracia en el actual contexto mundial, en el cual los hechos del 11 de septiembre de 2001 y sus ulteriores implicaciones politico-militares ban influido sustancialmente. También tenemos un mundo en el que las politicas neoliberales se han proclamado vencedoras por sobre cualquier otro tipo de organización social, económica y política. Hoy por boy, nos encontramos en un mundo donde la economía parece ser la que define los limites de las democracias, pero también los rasgos de las culturas. La expansión mundial del poderio de los transnacionales, se ha señalado, estaria atentando contra "las señas de identidad" de las culturas, amenazando con bomogeneizarlas. $Y$ esto no ocurre solamente en las naciones del llamado Tercer Mundo. La bomogeneización, esto es, la supresión de las diferencias en aras de un patrón cultural "universal", ha tocado también a las culturas del mundo desarrollado. El "boom" de la "cultura" de las transnacionales, que encantó a las multitudes que vivian en el llamado socialismo real, también ha permeado a aquellas culturas que se asumian a si mismas como poseedoras de una tradición sólida. Por otra parte, asistimos a un proceso de erosión de las llamadas democracias representativas, el cual deja abierto un espacio que parece estar siendo eficientemente capitalizado por propuestas dictatoriales, caudillistas o ultranacionalistas. Esta situación demanda, no sólo el aporte de los sectores que han luchado por construir una sociedad sobre la base de la justicia para las mayorias, sino también la reflexión profunda sobre estos problemas, los cuales demandan mucho más que soluciones esquemáticas o simplistas. Las conferencias que formaron parte del debate del IX Seminario Internacional del programa de diálogo Norte-Sur, desde una postura de honestidad intelectual, no pretenden descubrir la piedra filosofal con la que se podria transformar un presente sombrio en un futuro luminoso. Más que respuestas mágicas, las ponencias del seminario ayudan, al menos, a considerar elementos para plantearse adecuadamente cuáles son las preguntas. $Y$ esto es siempre un paso positivo.

En la presente edición de Realidad incluimos una muestra de los trabajos del Seminario, presentando los textos de las interven- 
ciones de Raúl Fornet-Betancourt, Karl-Otto Apel, Enrique Dussel, Franz Hinkelammert, Georges Labica y Carmen Bohórquez. También participaron intelectuales de la talla de Luis Villoro, Carlos Cullen, Hans Schelkshorn, Juan Antonio Senent, Mthokozisi Maseko, Edward Demenchonok y Sang-Bong Kim, cuyas intervenciones, lamentablemente, no incluimos por razones de espacio. $Y$ aunque no pretendan sustituir los aportes de estos importantes intelectuales, los trabajos aqui incluidos ofrecen un panorama representativo de lo que fue el Seminario. Complementamos el número con un ensayo del Decano de nuestra Facultad de Ciencias del Hombre, Héctor Samour, quien estuvo presente en las sesiones del Seminario, como moderador de una mesa de trabajo en la que participaron Carlos Cullen y Enrique Dussel. Aunque el trabajo de Samour no fue leido en el Seminario, la temática de éste -Zubiri y la Filosofía de la Liberación- no sólo va en consonancia con las interrogantes planteadas en los demás ensayos, sino que enriquece la presente edición.

Este número sale con la satisfacción de ofrecer al público una panorámica del estado de cosas del actual pensamiento mundial y de brindar nuevos elementos para el debate. 